\title{
FBP1 promotes ovarian cancer development through the acceleration of cell cycle transition and metastasis
}

\author{
XIFENG XIONG ${ }^{1}$, JINLI ZHANG ${ }^{1}$, XING HUA $^{2}$, WENJUAN CAO $^{1}$, SHENGNAN QIN $^{1}$, \\ LIBING DAI ${ }^{1}$, WEI LIU ${ }^{3}, \mathrm{ZHI} \mathrm{ZHANG}^{4}, \mathrm{XIAOJIAN} \mathrm{LI}^{4}$ and $\mathrm{ZHIHE} \mathrm{LIU}^{1}$ \\ ${ }^{1}$ Guangzhou Institute of Traumatic Surgery; Departments of ${ }^{2}$ Pathology, ${ }^{3}$ Breast Surgery, and ${ }^{4}$ Burns and Plastic Surgery, \\ Guangzhou Red Cross Hospital, Medical College, Jinan University, Guangzhou, Guangdong 510220, P.R. China
}

Received October 18, 2017; Accepted April 19, 2018

DOI: $10.3892 / \mathrm{ol} .2018 .8872$

\begin{abstract}
Epithelial ovarian cancer (EOC) is the fifth most common malignancy in women, with a 5-year mortality of $>70 \%$ in North America. As the symptoms are often not observed until the cancer has spread extensively, few women are diagnosed at an early stage of disease. Large-scale gene expression analyses have identified molecular subtypes within high-grade ovarian cancer with variable survival rates and drug resistance. The understanding of gene expression, the mechanisms underlying cancer processes and drug resistances have facilitated the development of targeted therapies. The far-upstream element (Fuse)-binding protein 1 (FBP1) is overexpressed in a number of malignancies such as hepatocellular carcinoma, and has been identified as an oncoprotein. In our early studies, FBP1 was demonstrated to physically interact with p53 and suppresses p53 transcription activity. In the present study, FBP1 expression increased as ovarian cancer developed. Among ovarian normal, adenoma and carcinoma tissues, the highest FBP1 expression was identified in carcinoma tissues. Furthermore FBP1 did not influence the apoptosis of ovarian carcinoma cells, yet enhanced cell cycle transition and metastasis. Therefore, it was hypothesized that FBP1 promotes ovarian cancer development through the acceleration of cell cycle transition and metastasis, and FBP1 is a novel potential biological marker for epithelial ovarian cancer diagnosis.
\end{abstract}

\section{Introduction}

Epithelial ovarian cancer (EOC) is the fifth most common malignancy in women, with a 5-year mortality of $>70 \%$ in North

Correspondence to: Dr Zhihe Liu, Guangzhou Institute of Traumatic Surgery, Guangzhou Red Cross Hospital, Medical College, Jinan University, 396 Tongfu Zhong Road, Guangzhou, Guangdong 510220, P.R. China

E-mail: zliu0731@163.com

Key words: epithelial ovarian cancer, fuse binding protein 1, cell cycle, metastasis
America (1). Combined surgery and cytotoxic therapy have previously been demonstrated to produce a favorable clinical response in $50-80 \%$ of patients (2). The platinum-paclitaxel combination regimen is utilized as the principal chemotherapy for advanced EOC, and yields response rates of $>80 \%$ and complete response rates of 40-60\% (3-7). Owing to the symptoms often not being observed until the cancer has spread extensively, $<25 \%$ of women are diagnosed at an early stage of disease (2). Large-scale gene expression analyses have identified molecular subtypes within high-grade ovarian cancer with variable survival rates and drug resistance $(8,9)$. These variations in gene expression may influence the outcomes of different treatment types. The understanding of gene expression, the mechanisms underlying cancer processes and drug resistances have facilitated the development of targeted therapies, such as small-molecule inhibitors. These agents target the proteins associating with cell viability/death, metastasis and angiogenesis. Previous studies have demonstrated breast cancer 1/2 (BRCA1/2) and DNA repair proteins, as markers for platinum treatment (8-10). Ribonucleotide reductase subunit M1 (RRM1) and DNA topoisomerase II- $\alpha$ (TOP2A) have been used as markers to predict the response to gemcitabine and anthracyclines for patients with ovarian cancer (11-13).

The far-upstream element (Fuse)-binding protein 1 (FBP1) has been identified as an anti-apoptotic and pro-proliferative oncoprotein that is overexpressed in a number of malignancies, including hepatocellular carcinoma (HCC) $(14,15)$, non small-cell lung cancer (16) and colorectal cancer (17). Importantly, nuclear enrichment of FBP1 is associated with poor overall survival of patients with liver cancer (14). FBP1 functions as a transcriptional regulator by binding to the single-stranded DNA element (fuse) and interacting with the basal transcriptional machinery $(18,19)$. The study of Rabenhorst et al (15) previously demonstrated that FBP1 serves a role in hematopoietic development and/or homeostasis. In our early studies, FBP1 was demonstrated to physically interact with p53 and suppress p53 transcription activity under radiation-induced cellular stress and facilitates hepatitis $C$ virus replication in hepatoma cells $(20,21)$. Silence of FBP1 increases the sensitivity of ovarian cancer cells to carboplatin (22).

Since FBP1 is always overexpressed in certain malignancies, the present study aimed to clarify the association between 
FBP1 expression and EOC development. We hypothesized that FBP1 enhances EOC development and that FBP1 is a novel potential biological marker for EOC diagnosis. The study also attempted to analyze the potential mechanisms underlying the promotion of FBP1 in EOC development.

\section{Materials and methods}

Patients and samples collection. The present study was conducted after informed consent was obtained from all subjects and the protocol was approved by the Medical Ethics Committee of Guangzhou Red Cross hospital of Medical College, Jinan University (Guangzhou, China). For immunohistochemical analysis, a total of 58 ovarian specimens were obtained from the Department of Pathology, Guangzhou Red Cross Hospital from January 2010 to June 2015 with a median age of 47.6 from 17.0-76.0 years old and assigned into three groups, including normal epithelial ovarian tissues (14 samples), epithelial ovarian adenoma tissues (25 samples) and epithelial ovarian cancer tissues (19 samples). None of the patients received preoperative therapies such as radiation, chemotherapy, or immunotherapy. All tissues were fixed with $10 \%$ formalin and then embedded in paraffin prior to sectioning.

Antibodies and reagents. The antibodies used for immunohistochemistry and western blot analysis were as follows: GAPDH (catalog no. 5174; 1:2,000) and FBP1 (cat. no. 72736; 1:1,000) antibodies were purchased from Cell Signaling Technology, Inc. (Danvers, MA, USA). Ki-67 (cat. no. 550609; 1:200) was obtained from BD Biosciences (Franklin Lakes, NJ, USA). Cyclin D1 (cat. no. sc-70899; 1:500), cyclin E (cat. no. sc-377100; 1:500), c-Myc (cat. no. sc-398624; 1:500), p21 (cat. no. sc-817; 1:500), p27 (cat. no. sc-1641; 1:500) and matrix metalloproteinase-2 (MMP-2; cat. no. sc-13594; 1:500) were obtained from Santa Cruz Biotechnology, Inc. (Dallas, TX, USA). Dulbecco's modified Eagle's medium (DMEM), fetal bovine serum (FBS) and L-glutamine, were obtained from Gibco; Thermo Fisher Scientific, Inc. (Waltham, MA, USA). The CellTiter $96^{\circledR}$ AQueous One Solution Reagent [3-(4,5-dimethylthiazol-2-yl)-5-(3-carboxymethoxyphenyl)-2(4-sulfophenyl)-2H-tetrazolium, inner salt; MTS] was purchased from Promega Corporation (Madison, WI, USA). Penicillin and streptomycin sulfate were purchased from GE Healthcare Life Sciences (Logan, UT, USA).

Cell culture and FBPI knockdown cell construction. The human ovarian cancer SKOV3 cells (Chinese Academy of Sciences Cell Bank) were cultured in DMEM with $10 \%(\mathrm{v} / \mathrm{v})$ FBS, $2 \mathrm{mM}$ L-glutamine, $100 \mathrm{U} / \mathrm{ml}$ penicillin and $100 \mu \mathrm{g} / \mathrm{ml}$ streptomycin at $37^{\circ} \mathrm{C}$ and $5 \% \mathrm{CO}_{2}$ in a humidified incubator.

FBP1-knockdown lentiviral particles (sc-43760) and control lentiviral particles (cat. no. sc-108080) were obtained from Santa Cruz Biotechnology, Inc. SKOV3 cells were plated in complete DMEM containing 10\% (v/v) FBS until they reached $70 \%$ confluence. Subsequently, cells were transfected with $20 \mu \mathrm{l}$ of either control lentiviral particles or FBP1-knockdown lentiviral particles $\left(1 \times 10^{6} \mathrm{IFU}\right)$ in serum-free medium according to the manufacturer's protocol. The transfection medium was replaced by fresh complete DMEM after
$6 \mathrm{~h}$ and the cells were incubated for another $48 \mathrm{~h}$ at $37^{\circ} \mathrm{C}$. Cells were collected after screening with $2.0 \mu \mathrm{g} / \mathrm{ml}$ puromycin for $\sim 2$ weeks and termed FBP1-knockdown (FBP1-KD) and FBP1 control (FBP1-C) SKOV3 cells, respectively.

Cell viability and plate colony formation assays. FBP1-C and FBP1-KD SKOV3 cells were plated into a 96-well plate at a density of $1 \times 10^{4}$ cells/well and cultures for $24 \mathrm{~h}$. Cell viability was measured using MTS in accordance with the manufacturer's (Promega Corporation) protocol, and the absorbance at the wavelength of $490 \mathrm{~nm}$ was read in an automated plate reader (Bio Tek Instruments Inc., Winooski, VT, USA). The experiments were repeated at least three times.

FBP1-C and FBP1-KD SKOV3 cells $\left(2.0 \times 10^{4}\right.$ cells/plate) were cultured in $5 \mathrm{ml}$ DMEM supplemented with $10 \%$ FBS in 10 -cm plates. After 14 days, colonies were washed with PBS, fixed with $10 \%$ methanol at $4^{\circ} \mathrm{C}$ for $30 \mathrm{~min}$ and stained with $1 \%$ crystal violet for $30 \mathrm{~min}$. The colony formation images were captured by camera.

Immunohistochemical staining. Formalin-fixed paraffin embedded ovarian tissue sections (5- $\mu \mathrm{m}$ thick) were deparaffinized (using 100\% of turpentine oil, three times for $10 \mathrm{~min} /$ time) and hydrated consecutively (100\% of ethanol for $3 \mathrm{~min}, 95 \%$ of ethanol for $3 \mathrm{~min}, 90 \%$ of ethanol for $3 \mathrm{~min}, 85 \%$ of ethanol for $3 \mathrm{~min}, 80 \%$ of ethanol for $3 \mathrm{~min}$, $75 \%$ of ethanol for $3 \mathrm{~min}$ and $\mathrm{H}_{2} \mathrm{O}$ for $3 \mathrm{~min}$ ). The sections were incubated with citrate buffer $(\mathrm{pH}$ 6.0) to retrieve the antigen using a microwave cooker. Endogenous peroxidase activity was quenched using $3 \%$ hydrogen peroxide $\left(\mathrm{H}_{2} \mathrm{O}_{2}\right)$. The sections were blocked with 10\% BSA (Wuhan Boster Biological Technology, Ltd., Wuhan, China) for $30 \mathrm{~min}$ at room temperature prior to incubation with rabbit anti-human FBP1 or Ki-67 antibody (diluted 1:500) overnight at $4^{\circ} \mathrm{C}$, and then incubated with HRP-conjugated secondary antibody (cat. no. 8114; 1:200; Cell Signaling Technology) for $1 \mathrm{~h}$ at room temperature. After washing with $\mathrm{PBS}$, the reaction was visualized by incubating the sections with DAB and hematoxylin for $5 \mathrm{~min}$ at room temperature. The negative control section was incubated with blocking reagent alone in the absence of primary antibody. Images were captured by an $\mathrm{x} 40$ objective and image processing and analyses were performed using the Image-Pro Plus 6.0 software (Media Cybernetics, Shanghai, China). The intensity of the immunohistochemical reaction was expressed as integral optical density (IOD) of DAB brown reaction products. The results of 5 separate measurements for each of sample were expressed as mean \pm standard deviation $(\mathrm{SD})$.

Western blot analysis. Cells were lysed for western blotting in modified RIPA buffer (150 mM NaCl, $1 \%$ NP-40, $50 \mathrm{mM}$ Tris- $\mathrm{Cl}$ [pH 8.0], 0.1\% SDS) supplemented with PMSF $(1 \mathrm{mM})$ protease and phosphatase inhibitor. Following rapid homogenization, the homogenates were incubated in ice for $30 \mathrm{~min}$ and centrifuged at $12,000 \mathrm{x} \mathrm{g}$ for $15 \mathrm{~min}$ at $4^{\circ} \mathrm{C}$. Protein concentrations were determined by bicinchoninic acid protein assay (Pierce; Thermo Fisher Scientific, Inc.). The protein samples (30-50 $\mu \mathrm{g} /$ lane) were resolved by SDS-PAGE (10-12\% gel) and transferred to polyvinylidene 
difluoride filter membranes (Merck KGaA, Darmstadt, Germany). Following transfer, membranes were blocked with $5 \%$ skimmed milk in TBS-Tween $(0.05 \mathrm{M}$ Tris, $0.15 \mathrm{M}$ $\mathrm{NaCl}, \mathrm{pH} 7.5,0.2 \%$ Tween-20) for $1 \mathrm{~h}$ at room temperature and then incubated at $4{ }^{\circ} \mathrm{C}$ overnight with primary antibodies of GAPDH, FBP1 (Cell Signaling Technology), Cyclin D1, Cyclin E, c-Myc, p21, p27 and MMP-2 (Santa Cruz). Membranes were washed with TBST for three times and then incubated with anti-rabbit/mouse HRP-labeled secondary antibodies for $1 \mathrm{~h}$ at room temperature, respectively, and detected with ECL-Plus detection systems (Pierce; Thermo Fisher Scientific, Inc.). Relative abundance was quantified by densitometry using Quantity One 4.6.7 software (Bio-Rad Laboratories, Inc., Hercules, CA, USA).

Cell cycle and cell apoptosis analysis. Flow cytometry was used for the analysis of cell cycle distribution and apoptosis. For cell cycle distribution, FBP1-C and FBP1-KD SKOV3 cells were collected and fixed in $70 \%(\mathrm{v} / \mathrm{v})$ ethanol overnight at $4^{\circ} \mathrm{C}$, and then incubated with $1 \mathrm{mg} / \mathrm{ml} \mathrm{RNase}$ A for $30 \mathrm{~min}$ at $37^{\circ} \mathrm{C}$. Cells were stained with $50 \mathrm{mg} / \mathrm{ml}$ propidium iodide (PI) (BD Biosciences) in PBS containing 1\% Triton $\mathrm{X}-100$. The data were acquired using a BD FACSCAN flow cytometer (FACSAria II, BD Biosciences) and analyzed using the BD CellQuest Pro software (BD Biosciences). For apoptosis, FBP1-C and FBP1-KD SKOV3 cells were firstly incubated with Annexin V-fluorescein isothiocyanate (FITC) (Beijing Biosea Biotechnology Co., Ltd., Beijing, China) for $30 \mathrm{~min}$ at $4^{\circ} \mathrm{C}$ in the dark, and then incubated with PI for $5 \mathrm{~min}$. Analysis was immediately performed by FACSAria II (BD Biosciences) according to the manufacturer's instructions.

Wound healing and Transwell migration assays. FBP1-C and FBP1-KD SKOV3 cells were seeded on 6-well plates at a density of $2 \times 10^{5}$ cells/well. The cells were scratched using a sterile $100 \mu 1$ micropipette tip and washed twice with PBS. The cells were cultured with complete DMEM with 10\% FBS for an additional $48 \mathrm{~h}$. Images were captured by a microscope at the $0-, 24-$ and 48 -h time-points.

The Transwell inserts $(8 \mu \mathrm{m}$ pore size, Corning Incorporated, Corning, NY, USA) were coated with $0.1 \%$ gelatin for $30 \mathrm{~min}$ at $37^{\circ} \mathrm{C}$. The bottom chambers of Transwell were filled with DMEM with $10 \%$ FBS, and the top chambers were seeded $1 \times 10^{5}$ cells per well (pretreated with mitomycin C) in $200 \mu \mathrm{l}$ DMEM (FBS free). After $24 \mathrm{~h}$ of incubation at $37^{\circ} \mathrm{C}$, the migrated cells were stained with $1 \%$ crystal violet for $30 \mathrm{~min}$ at room temperature. Images were captured using an Olympus inverted microscope (Olympus Corporation, Tokyo, Japan) at x200 magnification.

Statistical analysis. The data were derived from at least three independent experiments. Values reported are mean \pm SD. The data were analyzed using one-way analysis of variance and Student-Newman-Keuls post-hoc test by the SPSS 17.0 statistical package from SPSS Inc. (Chicago, IL, USA). The SPSS non-parametric Spearman's rank correlation was used to evaluate the correlation between FBP1 expression and the cell proliferation marker Ki-67. $\mathrm{P}<0.05$ was considered to indicate a statistically significant difference.

\section{Results}

FBP1 overexpression in ovarian tissues. To identify whether FBP1 is associated with the development of ovarian cancer, FBP1 expression was analyzed in epithelial ovarian normal, adenoma and carcinoma tissues by immunohistochemistry. As shown in Fig. 1A-a/b/c, FBP1 expression was identified in all three groups. FBP1 expression increased as cancer development and highest FBP1 expression was found in epithelial ovarian carcinoma tissues. A significant higher expression of FBP1 was identified in adenoma than in normal, or in carcinoma than in adenoma, or in carcinoma than in normal tissues (Fig. 1B). The expression of Ki-67, a key marker used to show cell proliferation, was also examined in all three groups. Mimicking the changes identified in FBP1, Ki-67 expression was increased in cancer development and the highest Ki-67 expression was found in epithelial ovarian cancer tissues. However, Ki-67 expression was very low in normal and adenoma tissues (Fig. 1C). Furthermore, the correlation between the expression of FBP1 and Ki-67 was analyzed by Spearman's rank correlation. The correlation coefficient was 0.782 at the $0.01 \mathrm{P}$-value level. This meant that a significant positive correlation was present between FBP1 and Ki-67. These data indicated that FBP1 is tightly associated with EOC development and cell proliferation.

Knockdown of FBP1 influenced cell proliferation. SKOV3 cells were transfected with control lentiviral particles or FBP1 knockdown lentiviral particles obtained from Santa Cruz, Biotechnology, Inc. screened with puromycin $(2.0 \mu \mathrm{g} / \mathrm{ml})$ for 2 weeks and polyclonal control or FBP1 knockdown SKOV3 cells were generated and named as FBP1-C and FBP-KD SKOV3 cells. As shown in Fig. 2A, the proliferation of FBP1-KD cells was significantly slower than that of the FBP1-C cells according to MTS assay. The colonies of FBP1-KD were significantly smaller than that of FBP1-C (Fig. 2B). In FBP1-C and FBP1-KD cells, the total number of apoptotic cells was $\sim 5.0 \%$, as analyzed by Annexin-V-FITC/PI flow cytometry (Fig. 2C and D). As shown in Fig. 2E, the expression of FBP1 in FBP1-KD cells was $\sim 15 \%$ of that in FBP1-C cells; this meant that the knockdown of FBP1 was successful. This data implied that that FBP1-knockdown did not influence apoptosis in SKOV3 cells. Based on these data, we believe that FBP1-knockdown influences cell proliferation; however, it does not influence apoptosis.

Knockdown of FBP1 inhibited cell cycle transition. Since FBP1 knockdown influenced cell proliferation, the effect of FBP1 on cell cycle progression was examined by flow cytometry. As shown in Fig. 2D, the percentage of cells in G1 phase was increased from $53.01 \%$ in FBP1-C cells to $72.86 \%$ in FBP1-KD cells. In contrast, the percentage of cells in S and G2 phase was decreased from 22.01 and $24.86 \%$ in FBP1-C cells to 13.16 and $13.98 \%$ in FBP1-KD cells. These data implied that FBP1 knockdown significantly inhibited cell cycle transition from G1 to S and G2 phase. Additionally, the expressions of proteins associated with cell cycle progression were analyzed. The proteins promoting cell cycle progression, including c-Myc, cyclin D1/E, were inhibited in FBP1-KD cells. However, proteins inhibiting cell cycle progression, such 

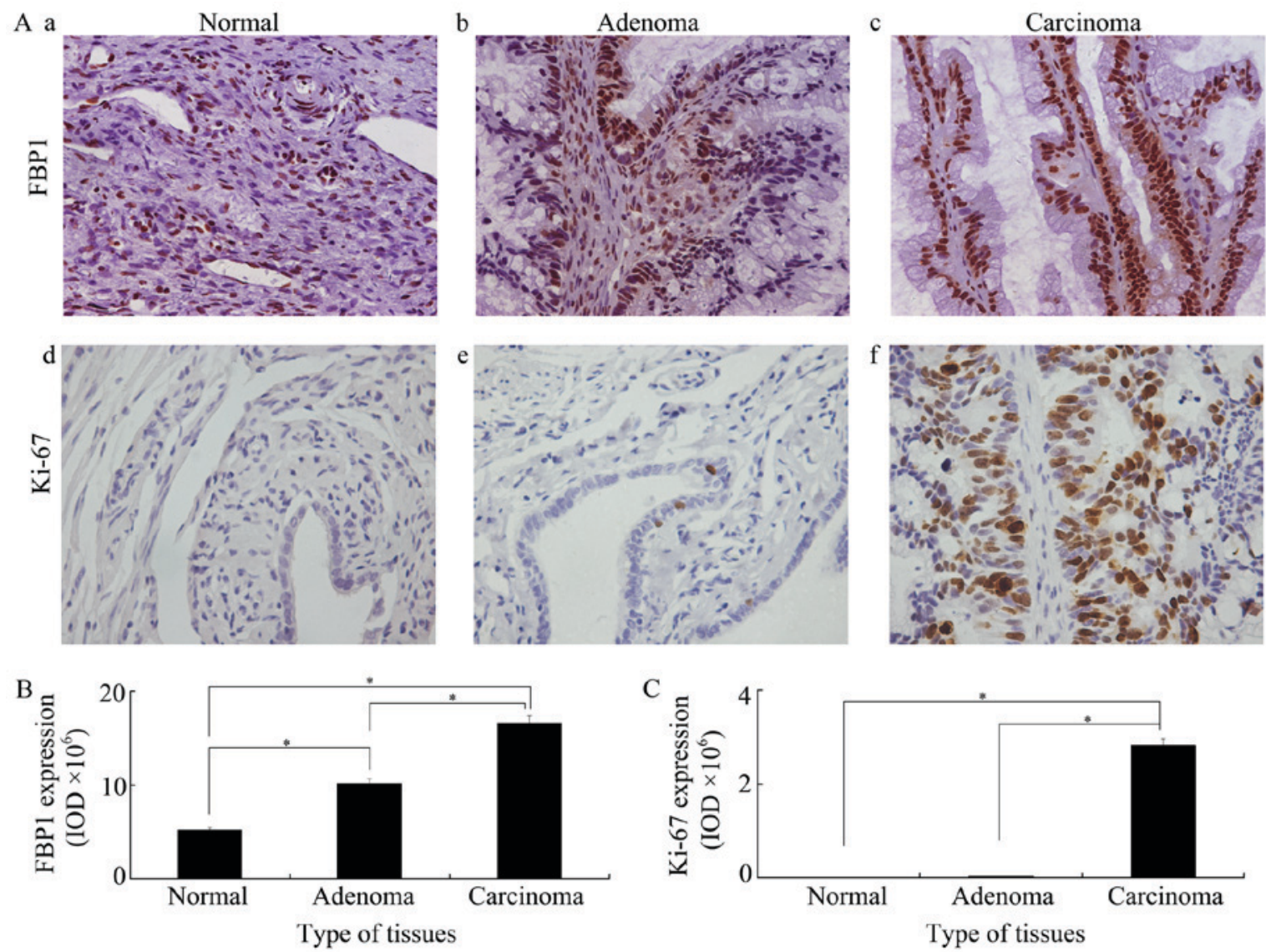

Figure 1. FBP1 and Ki-67 expressions in epithelial ovarian tissues. (A) FBP1 and Ki-67 expressions in (a and d) epithelial ovarian normal tissues, (b and e) adenoma tissues and (c and f) carcinoma tissues. Paraffin sections (5 mm) were deparaffinized and immunostaining was performed using anti-FBP1 or anti-Ki-67 antibodies. The antigen-antibody reactions were visualized with DAB and the images were captured by a 40 objective. Quantitative analysis of (B) FBP1 and (C) Ki-67 expression in epithelial ovarian normal, adenoma and carcinoma tissues by Image-Pro Plus 6 software. The intensity of DAB brown reactions was expressed as IOD. An analysis of variance with Student-Newman-Keuls post-hoc test was used to analyze statistical significance between groups. ${ }^{*} \mathrm{P}<0.05$ was considered to be statistically significance. IOD, integral optical density.

as p21 and p27, were increased in FBP1-KD cells (Fig. 2E). These data demonstrated that FBP1 influences cell cycle transition by adjusting the expression of cell cycle associated proteins.

FBP1 was associated with cell migration and metastasis. Metastasis is a key process that is required for cancer development (23). An improved understanding of the genetic evolution of metastasis can provide insight into the biology of cancer and contribute to the development of novel therapeutics. Therefore, the influence of FBP1 on ovarian cell migration and invasion was investigated.In the wound-healing assay, the migration of FBP1 knockdown SKOV3 cells was slower than that of FBP1 control cells (Fig. 3A). At 24 or $48 \mathrm{~h}$ later, the migration distance of FBP1-C cells was significant higher than that of FBP1-KD cells (Fig. 3B). Additionally, the results from the Transwell assay also revealed that FBP1 knockdown inhibited cell migration to the bottom chambers (Fig. 3C).

As MMPs are key regulators of cellular matrix degradation and promote cell migration (24), the expression of MMP-2 in FBP1-C and FBP1-KD SKOV3 cells was investigated and it was demonstrated that FBP1 knockdown inhibited the expression of MMP-2 (Fig. 3D). These data implied that FBP1 could promote cell migration and facilitate cell metastasis.

\section{Discussion}

In 2015, ovarian cancer was present in 1.2 million women and resulted in 0.16 million mortalities worldwide (24). The evolution of surgical techniques and chemotherapy regimens over the past three decades has resulted in improvements in the survival of patients with ovarian cancer (3). Despite high initial response rates for patients with chemotherapy, the majority of patients ultimately suffer from recurrence due to chemotherapy resistance (3). Therefore, novel approaches for the diagnosis and the treatment of ovarian cancer are urgently required. Improvements in the understanding of cancer biology and the underlying mechanisms governing the cancer processes have facilitated the development of targeted therapies, including small-molecule inhibitors and monoclonal antibodies (3). Certain ovarian cancers may be caused by mutations, such as the BRCA1 or BRCA2 mutation $(25,26)$ and dysregulation in the mitogen-activated protein kinase (MAPK) pathway (27). However, the majority of ovarian cancers can be attributed to a growing number of somatic aberrations (28). In the present study, the progression of ovarian cancer was positively associated with FBP1 expression. As the epithelial ovarian cancer progressed, the expression of FBP1 increased significantly. Furthermore, FBP1 was demonstrated to not only enhance cell proliferation but also promote cell metastasis; despite 
A

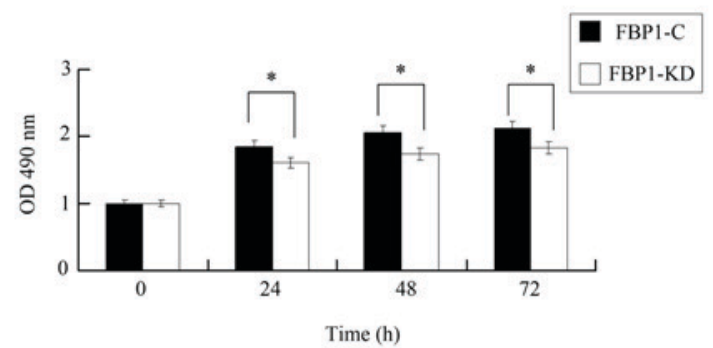

C

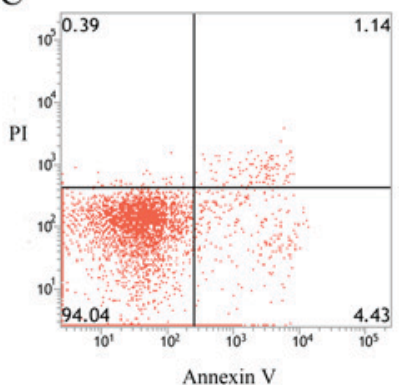

B
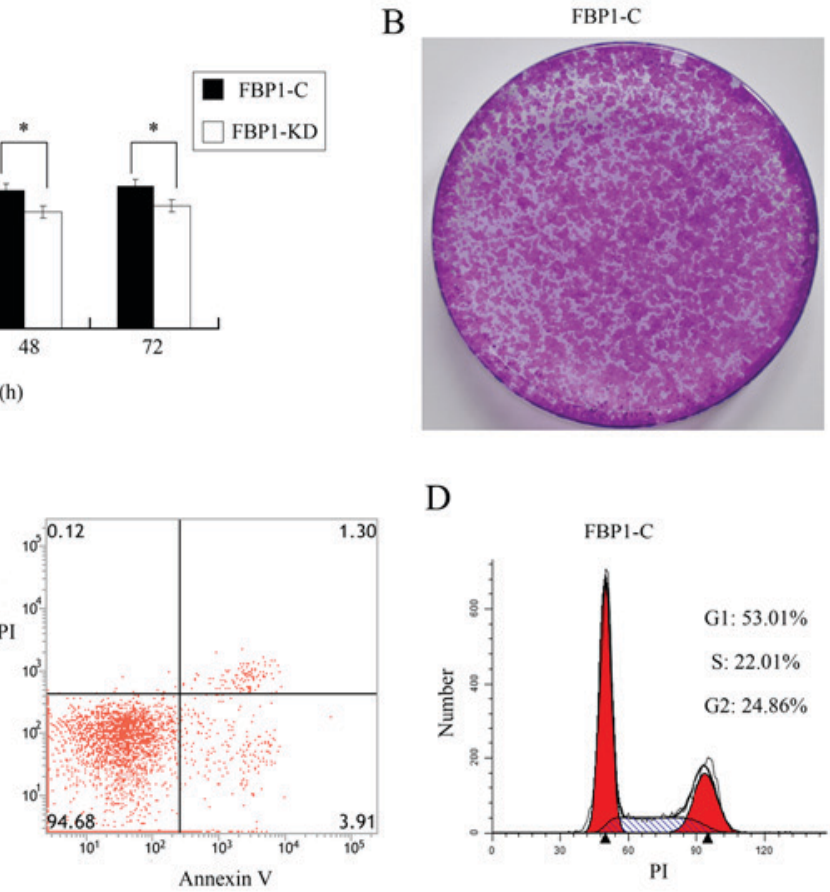

$\mathrm{D}$

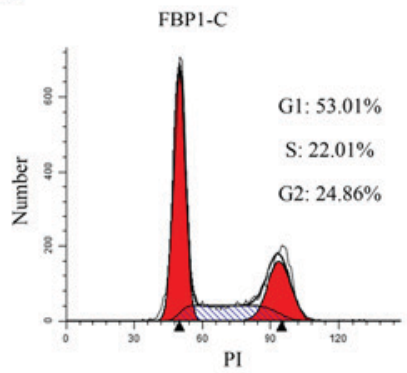

FBP1-KD

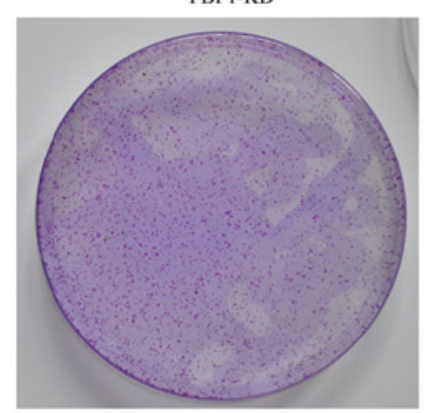

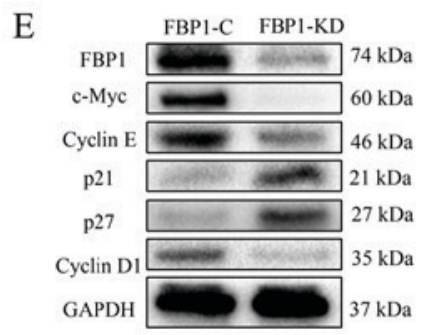

Figure 2. The knockdown of FBP1 inhibited cell proliferation and cell cycle transition. (A) FBP1 knockdown decreased cell proliferation examined by MTS assay. (B) FBP1 knockdown decreased colony formation. (C) FBP1 knockdown did not influence apoptotic occurrence in FBP1-C and FBP1-KD SKOV3 cells as analyzed by flow cytometry. (D) FBP1 knockdown inhibited cell cycle transition analyzed by flow cytometry. (E) The expression of cell cycle associating proteins in FBP1-C and FBP1-KD SKOV3 cells analyzed by western blotting. GAPDH acted as a loading control. Student's t-test was used to test statistical significance between groups. * $<0.05$ vs. FBP1-C. OD, optical density; FBP1-C, FBP1 normal control SKOV3 cells; FBP1-KD, FBP1 knockdown SKOV3 cells.

A
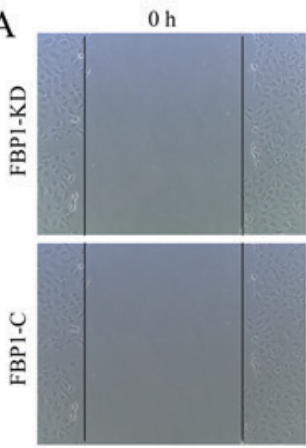

C

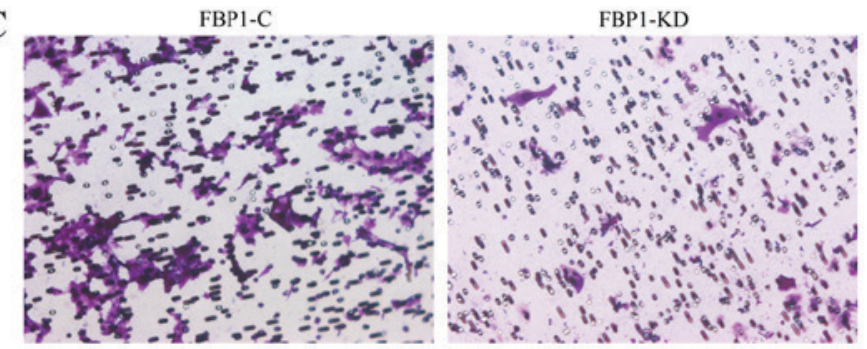

B

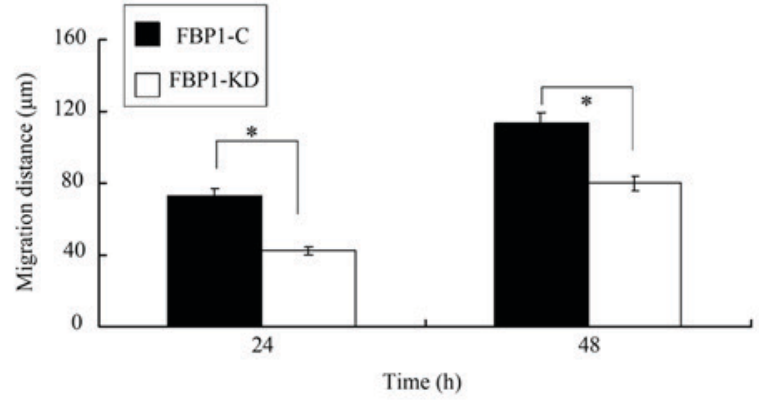

D

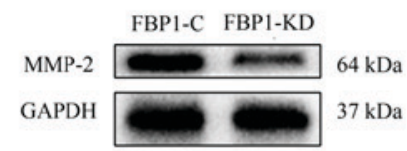

Figure 3. The knockdown of FBP1 inhibited cell metastasis. (A) Knockdown of FBP1 inhibited cell migration analyzed by wound healing experiment. (B) Migratory distance of the wound-healing assay (C) Knockdown of FBP1 inhibited cell migration as analyzed by the Transwell assay. (D) MMP-2 expression in FBP1-C and FBP1-KD SKOV3 cells. Student's t-test was used to test statistical significance between groups. * $\mathrm{P}<0.05$ vs. FBP1-C. 
FBP1 not affecting the occurrence of apoptosis. Therefore, we hypothesized that FBP1 is a potential target for novel treatment development and may serve as a diagnostic marker for ovarian cancer early screen. In our previous studies, FBP1 was demonstrated as a potential target of platinum and knockdown of FBP1 increased the sensitivity of ovarian cancer cells to carboplatin (22).

Decreased cell viability may be induced by cell cycle transition suppression and cell death activation. In the colony formation experiment of the present study, the knockdown of FBP1 was demonstrated to significantly inhibit colony formation and an increased number of cells were restrained in G1 phase and fewer cells were restrained in the S and G2 phases due to FBP1 knockdown. The cell cycle transition inhibiting proteins, such as p21 and p27, were induced by FBP1 knockdown. Conversely, cell cycle transition promoting proteins, including cyclin D1/E, c-Myc, were suppressed by FBP1 knockdown, and no influence of FBP1 knockdown on apoptosis was identified. When combined with the results of a previous study in which caspase 3 was not demonstrated to be activated in ovarian cancer cells (22), the results of the present study suggest that FBP1 knockdown significantly suppresses cell cycle transition; however, does not affect cell death in ovarian cancer cells.

Metastasis, the process by which a localized cancer becomes a systemic disease, is a complex, multistep process that requires cancer cells to detach from the primary tumor, travel, survive and proliferate in distant organs $(29,30)$. Metastatic tumors can occur in the early and late stages in the primary tumor $(29,30)$. An improved understanding of the genetic evolution of metastasis may provide insight into the biology of cancer and contribute to the development of novel therapeutics. MMPs have been traditionally considered to regulate a number of processes such as cell migration and metastasis $(31,32)$. MMPs are generally expressed at low levels; however, can be upregulated during tissue remodeling, inflammation, wound healing, and cancer progression $(33,34)$. It has been reported that the expression of MMP-2 was significantly higher in advanced ovarian cancer than in their benign or premalignant counterparts (35). In the present study, the knockdown of FBP1 was demonstrated to inhibit the migration of EOC cells, metastasis and the expression of MMP-2; an important member of the MMP family. Suggesting that FBP1 knockdown decreases the migration and metastasis through the inhibition of MMP expression.

The diagnosis of ovarian cancer has been challenging due to a lack of biomarkers in the early stage of disease, and the majority of patients eventually experience a median progression-free survival of 18 months (36). The current gold-standard chemotherapy, a platinum-paclitaxel combination regimen, is still far from optimum even though it is a significant improvement from previously administered treatments (3). A previous study demonstrated that FBP1 is a target protein of platinum-based treatment (37). In the present study, the progression of ovarian cancer was demonstrated to be positively associated with FBP1 expression. FBP1 enhanced cell cycle transition and metastasis, leading to the conclusion that FBP1 is a potential diagnostic marker for ovarian cancer in the early stage of disease.

\section{Acknowledgements}

The authors would like to thank the staff of the Guangdong Provincial Key Laboratory of Malignant Tumor Epigenetics and Gene Regulation, Sun Yat-Sen Memorial Hospital, Sun Yat-Sen University (Guangzhou, China) for support with regard to the flow cytometry experiments.

\section{Funding}

This study was supported by the National Natural Science Foundation of China (grant no. 81272222), the Science and Technology Program Foundation of Guangzhou (grant no. 2014J4100075), the Medical Science and Technology Research Foundation of Guangdong (grant no. B2016018) and the Medical and Health Science and Technology Project of Guangzhou (grant no. 20161A010019).

\section{Availability of data and materials}

All data generated or analyzed during this study are included in this article.

\section{Authors' contributions}

XX, ZL performed initial experimental design. XX, JZ, WC and SQ performed the experiments. XH, LD and WL prepared the tissue samples. XX and ZL wrote the paper. ZZ and XL made contirbutions to the experimental design and the manuscript.

\section{Ethics approval and consent to participate}

This study was conducted after ethics approval was obtained from the Medical Ethics Committee of Guangzhou Red Cross hospital of Medical College, Jinan University (Guangzhou, China). All contributors consented to participate.

\section{Consent for publication}

All authors read and approved the final manuscript.

\section{Competing interests}

The authors declared that they have no competing interests.

\section{References}

1. A JY, Wang GJ, Sun JG, Gu YC, Wu MS and Liu JH: Identification of phase I and phase II metabolites of Guanfu base A hydrochloride in human urine. Eur J Drug Metab Pharmacokinet 28: 265-272, 2003.

2. Berkenblit A and Cannistra SA: Advances in the management of epithelial ovarian cancer. J Reprod Med 50: 426-438, 2005.

3. Agarwal R and Kaye SB: Ovarian cancer: Strategies for overcoming resistance to chemotherapy. Nat Rev Cancer 3: 502-516, 2003.

4. Ozols RF, Bundy BN, Greer BE, Fowler JM, Clarke-Pearson D, Burger RA, Mannel RS, DeGeest K, Hartenbach EM and Baergen R; Gynecologic Oncology Group: Phase III trial of carboplatin and paclitaxel compared with cisplatin and paclitaxel in patients with optimally resected stage III ovarian cancer: A Gynecologic Oncology Group study. J Clin Oncol 21: 3194-3200, 2003. 
5. du Bois A, Neijt JP and Thigpen JT: First line chemotherapy with carboplatin plus paclitaxel in advanced ovarian cancer-a new standard of care? Ann Oncol 10 (Suppl 1): S35-S41, 1999.

6. Biagi JJ and Eisenhauer EA: Systemic treatment policies in ovarian cancer: The next 10 years. Int J Gynecol Cancer 13 (Suppl 2): S231-S240, 2003.

7. Neijt JP, Engelholm SA, Tuxen MK, Sorensen PG, Hansen M, Sessa C, de Swart CA, Hirsch FR, Lund B and van Houwelingen HC: Exploratory phase III study of paclitaxel and cisplatin versus paclitaxel and carboplatin in advanced ovarian cancer. J Clin Oncol 18: 3084-3092, 2000.

8. Krivak TC, Darcy KM, Tian C, Armstrong D, Baysal BE, Gallion H, Ambrosone CB and DeLoia JA; Gynecologic Oncology Group Phase III Trial: Relationship between ERCC1 polymorphisms, disease progression, and survival in the Gynecologic Oncology Group Phase III Trial of intraperitoneal versus intravenous cisplatin and paclitaxel for stage III epithelia ovarian cancer. J Clin Oncol 26: 3598-3606, 2008.

9. Krivak TC, Darcy KM, Tian C, Bookman M, Gallion H, Ambrosone CB and Deloia JA: Single nucleotide polypmorphisms in ERCC1 are associated with disease progression, and survival in patients with advanced stage ovarian and primary peritoneal carcinoma; a Gynecologic Oncology Group study. Gynecol Oncol 122: 121-126, 2011.

10. Dann RB, DeLoia JA, Timms KM, Zorn KK, Potter J, Flake DD II, Lanchbury JS and Krivak TC: BRCA1/2 mutations and expression: response to platinum chemotherapy in patients with advanced stage epithelial ovarian cancer. Gynecol Oncol 125: 677-682, 2012.

11. Reynolds C, Obasaju C, Schell MJ, Li X, Zheng Z, Boulware D, Caton JR, Demarco LC, O'Rourke MA, Shaw Wright G, et al: Randomized phase III trial of gemcitabine-based chemotherapy with in situ RRM1 and ERCC1 protein levels for response prediction in non-small-cell lung cancer. J Clin Oncol 27: 5808-5815, 2009.

12. Gong W, Zhang X, Wu J, Chen L, Li L, Sun J, Lv Y, Wei X, $\mathrm{Du} \mathrm{Y}$, Jin $\mathrm{H}$ and Dong J: RRM1 expression and clinical outcome of gemcitabine-containing chemotherapy for advanced non-small-cell lung cancer: A meta-analysis. Lung Cancer 75 : 374-380, 2012

13. Erriquez J, Becco P, Olivero M, Ponzone R, Maggiorotto F, Ferrero A, Scalzo MS, Canuto EM, Sapino A, Verdun di Cantogno L, et al: TOP2A gene copy gain predicts response of epithelial ovarian cancers to pegylated liposomal doxorubicin: TOP2A as marker of response to PLD in ovarian cancer. Gynecol Oncol 138: 627-633, 2015.

14. Malz M, Weber A, Singer S, Riehmer V, Bissinger M, Riener MO, Longerich T, Soll C, Vogel A, Angel P, et al: Overexpression of far upstream element binding proteins: A mechanism regulating proliferation and migration in liver cancer cells. Hepatology 50: $1130-1139,2009$.

15. Rabenhorst U, Beinoraviciute-Kellner R, Brezniceanu ML, Joos S, Devens F, Lichter P, Rieker RJ, Trojan J, Chung HJ, Levens DL and Zörnig M: Overexpression of the far upstream element binding protein 1 in hepatocellular carcinoma is required for tumor growth. Hepatology 50: 1121-1129, 2009.

16. Singer S, Malz M, Herpel E, Warth A, Bissinger M, Keith M, Muley T, Meister M, Hoffmann H, Penzel R, et al: Coordinated expression of stathmin family members by far upstream sequence element-binding protein-1 increases motility in non-small cell lung cancer. Cancer Res 69: 2234-2243, 2009.

17. Chen M, Zhang J, Li N, Qian Z, Zhu M, Li Q, Zheng J, Wang X and Shi G: Promoter hypermethylation mediated downregulation of FBP1 in human hepatocellular carcinoma and colon cancer. PLoS One 6: e25564, 2011.

18. Avigan MI, Strober B and Levens D: A far upstream element stimulates c-myc expression in undifferentiated leukemia cells. J Biol Chem 265: 18528-18545, 1990.
19. He L, Weber A and Levens D: Nuclear targeting determinants of the far upstream element binding protein, a c-myc transcription factor. Nucleic Acids Res 28: 4558-4565, 2000.

20. Dixit U, Liu Z, Pandey AK, Kothari R and Pandey VN: Fuse binding protein antagonizes the transcription activity of tumor suppressor protein p53. BMC Cancer 14: 925, 2014.

21. Dixit U, Pandey AK, Liu Z, Kumar S, Neiditch MB, Klein KM and Pandey VN: FUSE binding protein 1 facilitates persistent hepatitis c virus replication in hepatoma cells by regulating tumor suppressor p53. J Viro 89: 7905-7921, 2015.

22. Zhang J, Xiong X, Hua X, Cao W, Qin S, Dai L, Liang P, Zhang H and Liu Z: Knockdown of FUSE binding protein 1 enhances the sensitivity of epithelial ovarian cancer cells to carboplatin. Oncol Lett 14: 5819-5824, 2017.

23. Steeg PS and Theodorescu: Metastasis: A therapeutic target for cancer. Nat Clin Pract Oncol 5: 206-219, 2008.

24. Rodriguez D, Morrison CJ and Overall CM: Matrix metalloproteinases: What do they not do? New substrates and biological roles identified by murine models and proteomics. Biochim Biophys Acta 1803: 39-54, 2010.

25. Pal T, Permuth-Wey J, Betts JA, Krischer JP, Fiorica J, Arango H, LaPolla J, Hoffman M, Martino MA, Wakeley K, et al: BRCA1 and BRCA2 mutations account for a large proportion of ovarian carcinoma cases. Cancer 104: 2807-2816, 2005

26. Risch HA, McLaughlin JR, Cole DE, Rosen B, Bradley L, Fan I, Tang J, Li S, Zhang S, Shaw PA and Narod SA: Population BRCA1 and BRCA2 mutation frequencies and cancer penetrances: A kin-cohort study in Ontario, Canada. J Natl Cancer Inst 98: 1694-1706, 2006.

27. Cancer Genome Atlas Research Network: Integrated genomic analyses of ovarian carcinoma. Nature 474: 609-615, 2011.

28. Bast RC Jr, Hennessy B and Mills GB: The biology of ovarian cancer: New opportunities for translation. Nat Rev Cancer 9: 415-428, 2009

29. Massagué J and Obenauf AC: Metastatic colonization by circulating tumour cells. Nature 529: 298-306, 2016.

30. Talmadge JE and Fidler IJ: AACR centennial series: The biology of cancer metastasis: historical perspective. Cancer Res 70: 5649-5669, 2010

31. Zitka O, Kukacka J, Krizkova S, Huska D, Adam V, Masarik M, Prusa R and Kizek R: Matrix metalloproteinases. Curr Med Chem 17: 3751-3768, 2010.

32. Butler GS and Overall CM: Updated biological roles for matrix metalloproteinases and new 'intracellular' substrates revealed by degradomics. Biochemistry 48: 10830-10845, 2009.

33. Kessenbrock K, Plaks V and Werb Z: Matrix metalloproteinases: regulators of the tumor microenvironment. Cell 41: 52-67, 2010.

34. Hadler-Olsen E, Fadnes B, Sylte I, Uhlin-Hansen L and Winberg JO: Regulation of matrix metalloproteinase activity in health and disease. FEBS J 278: 28-45, 2011.

35. Sakata K, Shigemasa K, Nagai N and Ohama K: Expression of matrix metalloproteinases (MMP-2, MMP-9, MT1-MMP) and their inhibitors (TIMP-1, TIMP-2) in common epithelial tumors of the ovary. Int J Oncol 17: 673-681, 2000.

36. Greenlee RT, Hill-Harmon MB, Murray T and Thun M: Cancer statistics, 2001. CA Cancer J Clin 51: 15-36, 2011.

37. Pénzváltó Z, Lánczky A, Lénárt J, Meggyesházi N, Krenács T, Szoboszlai N, Denkert C, Pete I and Győrffy B: MEK1 is associated with carboplatin resistance and is a prognostic biomarker in epithelial ovarian cancer. BMC Cancer 14: 837, 2014. International (CC BY-NC-ND 4.0) License. 